\title{
RPN2 expression predicts response to docetaxel in oesophageal squamous cell carcinoma
}

\author{
J Kurashige',2, M Watanabe', M Iwatsuki', K Kinoshita', S Saito', Y Nagai', T Ishimoto', Y Baba', K Mimori' \\ and $\mathrm{H} \mathrm{Baba*}{ }^{*}, \mathrm{M}$
}

'Department of Gastroenterological Surgen, Graduate School of Medical Sciences, Kumamoto University, I-I-I Honjo, Kumamoto, Kumamoto 860-8556, Japan; ²Department of Surgery, Kyushu University Beppu Hospital, 4546 Tsurumiji Tsurumihara, Beppu, Oita 874-0838, Japan

BACKGROUND: Neoadjuvant chemotherapy - often using docetaxel in various combinatorial regimens - is a standard treatment choice for advanced oesophageal squamous cell carcinoma (ESCC) in Japan. However, no useful markers exist that predict docetaxel's effects on ESCC. Ribophorin II (RPN2) silencing, which reduces glycosylation of P-glycoproteins and decreases membrane localisation, promotes docetaxel-dependent apoptosis. We investigated whether RPN2 expression in ESCC biopsy specimens could be a predictive biomarker in docetaxel-based neoadjuvant chemotherapy.

METHODS: We evaluated RPN2 expression immunohistochemically in biopsy specimens from 79 patients with node-positive ESCC, who received docetaxel-based adjuvant chemotherapy, and compared clinical and pathological responses between the RPN2-positive and RPN2-negative groups. We also studied susceptibility of RPN2-suppressed ESCC cells to docetaxel.

RESULTS: The RPN2-negative group had better clinical and pathological responses to docetaxel than the RPN2-positive group. We also found RPN2 suppression to alter docetaxel susceptibility in vitro.

CONCLUSION: Expression of RPN2 in biopsy specimens could be a useful predictive marker for response to docetaxel-based neoadjuvant chemotherapy in ESCC.

British Journal of Cancer (2012) I07, 1233-1238. doi:I0.1038/bjc.2012.396 www.bjcancer.com

Published online 6 September 2012

(C) 2012 Cancer Research UK

Keywords: docetaxel; neoadjuvant chemotherapy; ESCC; RPN2; predictive marker

In Japan, prognosis of patients with oesophageal squamous cell carcinoma (ESCC) has improved over several decades, mainly owing to improved surgical techniques, such as three-field lymph node dissection (Akiyama et al, 1994; Ando et al, 2000). However, survival of patients with node-positive ESCC is still unsatisfactory. Therefore, clinical studies to evaluate the efficacy of adjuvant chemotherapy for resectable ESCC have been conducted. JCOG 9204, which compared postoperative chemotherapy with surgery alone, found that two courses of 5-fluorouracil (5-FU) and cisplatin (FP) prolonged survival of patients with node-positive stage II/III ESCC (Ando et al, 2003). JCOG 9907 compared preoperative chemotherapy with postoperative chemotherapy and found the preoperative chemotherapy arm had significantly better overall survival than did the postoperative chemotherapy arm (Ando et al, 2012). On the basis of these findings, current standard treatment for resectable stage II/III ESCC in Japan relies on neoadjuvant chemotherapy followed by surgery.

However, an optimal neoadjuvant chemotherapy regimen for ESCC has not been established. Although the FP combination has been a standard regimen for advanced or metastatic ESCC (Kelsen et al, 1998; Ancona et al, 2001; Ando et al, 2012), its response rate is not sufficiently high. Recently, docetaxel combined with FP (DCF) was tested as induction therapy for patients with

*Correspondence: Dr H Baba; E-mail: hdobaba@kumamoto-u.ac.jp Received 19 March 2012; revised I August 2012; accepted 3 August 2012; published online 6 September 2012 node-positive ESCC, and had a good result (Overman et al, 2010; Watanabe et al, 2011; Yamasaki et al, 2011). We consider docetaxel to be a key drug for treating patients with ESCC.

Docetaxel-based combination chemotherapy is highly toxic. Therefore, if tumours do not respond to this chemotherapy, its use is not merely pointless, but actually harmful. Worse, as neoadjuvant chemotherapy delays surgical treatment, there is a risk of losing the opportunity to cure non-responders. Therefore, molecular markers that predict response to chemotherapy would be extremely helpful in selecting patients who may benefit from neoadjuvant therapy.

Recently, Honma et al (2008) revealed that downregulation of ribophorin II (RPN2), which is part of an $\mathrm{N}$-oligosaccharyl transferase complex, efficiently induced apoptosis in docetaxelresistant human breast cancer cells in the presence of docetaxel. Silencing of RPN2 reduced glycosylation of the P-glycoprotein and decreased membrane localisation, thereby sensitising cancer cells to docetaxel (Honma et al, 2008). These findings suggest that RPN2 expression is a candidate predictive marker for resistance to docetaxel-based chemotherapy. There is little current information regarding either RPN2 expression in ESCC or correlation between its expression and resistance to docetaxel. In this study, we examined RPN2 expression immunohistochemically in pretreatment endoscopic biopsy samples from ESCC patients, and assessed the correlation between RPN2 expression and response to neoadjuvant chemotherapy. In addition, we investigated whether RPN2 expression levels affected docetaxel sensitivity in ESCC in vitro. 
Table I RPN2 expression and the clinicopathological features

\begin{tabular}{|c|c|c|c|c|}
\hline \multirow[b]{2}{*}{ Features } & \multirow[b]{2}{*}{$\begin{array}{c}\text { Total } \\
(n=79)\end{array}$} & \multicolumn{2}{|c|}{ RPN2 } & \multirow[b]{2}{*}{$P$-value } \\
\hline & & $\begin{array}{l}\text { Positive } \\
(n=51)\end{array}$ & $\begin{array}{c}\text { Negative } \\
(n=28)\end{array}$ & \\
\hline Age (years) & & & & 0.100 \\
\hline High $(\geqslant 70)$ & 39 & 29 & 10 & \\
\hline Low $(<70)$ & 40 & 22 & 18 & \\
\hline Sex & & & & 0.763 \\
\hline Male & 66 & 42 & 24 & \\
\hline Female & 13 & 9 & 4 & \\
\hline Depth of tumour invasion & & & & 0.383 \\
\hline cTI & 6 & 3 & 3 & \\
\hline cT2 & 16 & 8 & 8 & \\
\hline cT3 & 48 & 33 & 15 & \\
\hline cT4 & 9 & 7 & 2 & \\
\hline Distant metastasis & & & & 0.705 \\
\hline Absent & 71 & 45 & 26 & \\
\hline Present & 8 & 6 & 2 & \\
\hline Stage & & & & 0.638 \\
\hline$\|$ & 10 & 5 & 5 & \\
\hline III & 43 & 29 & 14 & \\
\hline IV & 26 & 17 & 9 & \\
\hline \multicolumn{5}{|l|}{ Therapy after DCF } \\
\hline Esophagectomy & 49 & 34 & 15 & 0.573 \\
\hline Continue DCF & 11 & 6 & 5 & \\
\hline Chemoradiation & 18 & 10 & 8 & \\
\hline Best supportive care & I & I & 0 & \\
\hline
\end{tabular}

Abbreviations: DCF = docetaxel combined with FP; RPN2 = ribophorin II. Analysed by Fisher's exact test.

\section{MATERIALS AND METHODS}

\section{Patients and samples}

We used paraffin blocks of 79 specimens endoscopically biopsied from patients with node-positive ESCC before treatment with the modified DCF regimen $\left(60 \mathrm{mg} \mathrm{m}^{-2}\right.$ docetaxel on day 1 ; $350 \mathrm{mg} \mathrm{m}^{-2} 5$-FU and $6 \mathrm{mg} \mathrm{m}^{-2}$ cisplatin on days 1-5) at Kumamoto University Hospital for this study from March 2008 to October 2011. Before therapy, all patients underwent upper gastroenterological fiberscope, oesophagography, enhanced CT imaging from neck to abdomen and ${ }^{18}$ F-fluorode-oxyglucose positron emission tomography (FDG-PET) for tumour staging according to the TNM classification (ver. 6).

After being diagnosed with node-positive ESCC, all patients received combination induction chemotherapy of the DCF regimen given every 3 weeks for two rounds; their clinical response was then evaluated. Imaging by FDG-PET CT, upper gastroenterological fiberscope and oesophagography was conducted in all patients post chemotherapy ( 2 weeks after the end of therapy). After two rounds of chemotherapy, 49 patients underwent oesophageal resection, 11 patients continued DCF regimen, 18 patients underwent chemoradiation (DCF + radiation) therapy and 1 patient received the best supportive care. Clinical data are summarised in Table 1. Informed consent was obtained from all patients who participated in this study. This study was approved by the Institute Review Board of the Graduate School of Medical Science, Kumamoto University (approval number: 236; 2 August 2008).

\section{Evaluation of clinical responses to DCF}

We evaluated clinical responses to DCF chemotherapy by (1) the Response Evaluation Criteria in Solid Tumors (RECIST) v1.0; (2) World Health Organization (WHO) criteria: upper gastroenterological fiberscope and oesophagography assessments based on criteria defined by the WHO, including complete response (CR), disappearance of all known disease, partial response (PR), $\leqslant 50 \%$ decrease in entire tumour burden, stable disease (SD); $<50 \%$ decrease or $<25 \%$ increase in entire tumour burden and progressive disease $(\mathrm{PD}), \geqslant 25 \%$ increase in the entire tumour burden or appearance of new lesions; and (3) histopathological criteria: for the 49 patients who underwent oesophageal resection, histopathological tumour regression in response to chemotherapy was assessed by evaluating the resected tumours according to a three-grade score established by the Japanese Guidelines for the Clinical and Pathologic Studies on Carcinoma of the Esophagus, with histopathological effects classified into four categories, from grade 0 to 3 (grade definitions shown in Supplementary Table 1).

\section{Response analysis by FDG-PET}

We evaluated responses to DCF chemotherapy by changes in standardised uptake value (SUV), which was obtained using FDG-PET values before and after DCF chemotherapy, and calculated the percentage decrease in $\mathrm{SUV}_{\max }$ rate of primary tumours during chemotherapy using the formula: ((preSUV $\mathrm{max}_{\max }$ postSUV $\left.V_{\text {max }}\right) /$ preSUV $\left._{\text {max }}\right) \times 100($ Brucher et al, 2001).

\section{Immunohistochemical staining for RPN2}

Immunostaining was done on $5-\mu \mathrm{m}$ tissue sections mounted on silane-coated slides. Each paraffin section was deparaffinised with xylene, followed by antigen retrieval. Antigen retrieval was carried out using $0.01 \mathrm{M}$ ( $\mathrm{pH}$ 9.0) buffer and microwaved for $15 \mathrm{~min}$. Ribophorin II protein expression was evaluated using a polyclonal antibody specific for RPN2 (N-20, 1:200, Santa Cruz Biotechnology, Santa Cruz, CA, USA) and incubating overnight, and with the secondary antibody (Histofine MAX PO, Nichirei, Tokyo, Japan) for 30 min. Ribophorin II cytoplasmic expression was assigned intensity grades - no staining: 0, weak staining: 1 , moderate staining: 2 and strong staining: 3 (Figure1 shows examples of RPN2 staining). Tumour cells with weaker staining patterns than normal epithelial cells - weak (1), or non-staining (0) - were considered to have negative expression. Expression was independently evaluated by two of the authors (JK and YB) using a blind protocol design; observers had no information on clinical outcome or any other clinicopathological data.

\section{Cell culture}

Human oesophageal carcinoma cell lines TE1 and 14 (TE1/14) were provided by the Cell Resource Center for Biomedical Research Institute of Development, Aging and Cancer, Tohoku University, Japan. All cells were grown in RPMI 1640 (Cambrex, East Rutherford, NJ, USA) supplemented with $10 \%$ foetal bovine serum (Sigma-Aldrich, St Louis, MO, USA), and incubated in a humidified chamber supplemented with $5 \% \mathrm{CO}_{2}$.

\section{Transfection of small interfering RNA}

Small interfering RNA (siRNA) against RPN2 and control nontargeting siRNA were obtained from Invitrogen, Inc. (Carlsbad, CA, USA), Stealth RNAi sequences: RPN2 (5'-GACAUCUCUUCAG GCCUGACAAUUU- $3^{\prime}$ ). The non-silencing control siRNA, which has no sequence homology to any known human gene sequence, was used as a control for non-specific effects in all experiments. Subconfluent human prostate cells were transfected with siRNA using Lipofectamine 2000 transfection regent (Invitrogen) following the manufacturer's instructions. Two days after transfection, the efficacy of siRNA knockdown was assessed using quantitative reverse-transcription PCR (qRT-PCR) and immunoblotting. The optimal amount of siRNA used for transfection was determined to be $20 \mathrm{nmoll}^{-1}$, and the siRNA sequence that best reduced $>90 \%$ of RPN2 expression was identified. 

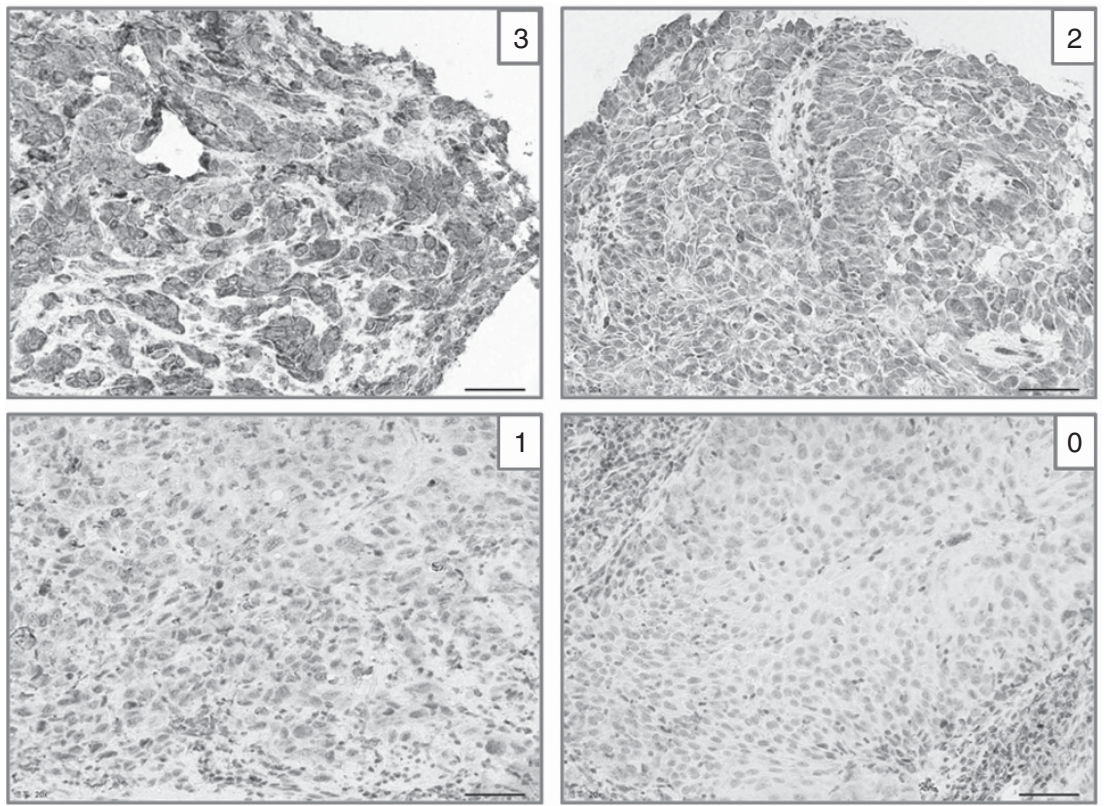

Figure I Immunohistochemical staining of RPN2 protein in ESCC tissues. RPN2 protein expression was detected in the cytoplasm. We graded RPN2 protein expression as null (0), weak (I), moderate (2) or strong (3). Tumour cells that exhibited weaker staining patterns than normal epithelial cells - weak (I) or null (0) - were defined as RPN2 negative. Scale bar is $50 \mu \mathrm{m}$.

\section{Chemotherapy dose-response curve}

To assess the effect of RPN2 on docetaxel sensitivity, $3 \times 10^{3}$ cells were seeded onto 96 -well microtitre plates. To assess the effect of the combination treatment of RPN2 silencing plus chemotherapy, TE1/14 cells were transfected with $20 \mathrm{nmoll}^{-1}$ of stealth siRNA against RPN2 for $24 \mathrm{~h}$. Cells were then treated with docetaxel at increasing concentrations $(0.5,1.0,5.0,10,50,100,500$ or $1000 \mathrm{nM})$ for $48 \mathrm{~h}$. The cell survival rate was determined using the WST- 8 assay with Cell Counting Kit-8 (Dojin Laboratories, Kumamoto, Japan). Absorbance was measured at $450 \mathrm{~nm}$. Cell viability was determined using an MTT assay.

\section{Western blot analysis}

To isolate proteins, cells harvested onto six-well plates were washed once in PBS and lysed in lysis buffer $\left(25 \mathrm{mmoll}^{-1}\right.$ Tris-HCl pH 7.4, $100 \mathrm{mmoll}^{-1} \mathrm{NaCl}, 2 \mathrm{mmol} 1^{-1}$ EDTA, $1 \%$ Triton $\mathrm{X}$ with $10 \mu \mathrm{g} \mathrm{ml}^{-1}$ aprotinin, $10 \mu \mathrm{g} \mathrm{ml}^{-1}$ leupeptin, $1 \mathrm{mmoll}^{-1}$ $\mathrm{Na}_{3} \mathrm{VO}_{4}, 1 \mathrm{mmoll}^{-1}$ phenylmethylsulfonylfluoride). Each protein sample $(15 \mu \mathrm{g})$ was resolved on SDS-PAGE, transferred onto a polyvinylidene difluoride membrane and incubated with a polyclonal antibody against RPN2 (N-20, 1:200, Santa Cruz Biotechnology) or $\beta$-actin (1:2000; Sigma-Aldrich). The signals were detected using secondary antibodies labelled with HPL and ECL Detection System (GE Healthcare, Little Chalfont, UK).

\section{RNA isolation and real-time qRT-PCR}

Total RNA, including miRNA, was isolated from tissue samples and cell lines using RNAeasy (Qiagen, Hilden, Germany), and eluted into $100 \mu \mathrm{l}$ of heated Elution Solution according to the manufacturer's protocol. The purity and concentration of all RNA samples were quantified using NanoDrop ND-1000 (Thermo Scientific, Wilmington, DE, USA). Expression levels of RPN2 were quantified using a SYBR Green qRT-PCR with LightCycler 480 SYBR Green I Master (Roche Diagnostics, Basel, Switzerland) and normalised to GAPDH. SYBR Green real-time RT-PCR was done using primers specific for RPN2 (forward: $5^{\prime}$-ATCTAACCTTG ATCCCAGCAATGTG-3'; reverse: 5'-CTGCCAGAAGCAGATCTTT
GGTC-3') and GAPDH (forward: $5^{\prime}$-TTGGTATCGTGGAAGGACT C-3'; reverse: 5'-AGTAGAGGCAGGGATGATGT-3'). All qRT-PCR was executed on the LightCycler 480 System II (Roche Diagnostics). Relative amounts of RPN2 were measured using the $2^{-\Delta \Delta C T}$ method. All qRT-PCR reactions were performed in triplicate.

\section{Statistical analysis}

All experiments were repeated at least three times. Continuous variables were expressed as medians and ranges. Relationships between RPN2 expression and patient clinicopathological characteristics were analysed using Fisher's exact test. $P<0.05$ was considered to be significant. All statistical analyses were performed using the SPSS v. 13.0 software programme (SPSS, Inc., Chicago, IL, USA).

\section{RESULTS}

\section{Patient characteristics and RPN2 expression}

Of the 79 patients with ESCC, who were evaluated in this study, we found $64.6 \%$ (51 out of 79) of patients belonged in the RPN2positive group and $35.4 \%$ (28 out of 79 ) belonged in the RPN2negative group (Figure 1). Expression of RPN2 protein was localised in the cytoplasm. Although we also examined correlations between RPN2 expression and clinicopathological features, such as patient age and sex, tumour depth, presence of distant metastasis and clinical stage, we found no significant correlations between RPN2 expression and clinicopathological factors (Table 1).

\section{Correlation between RPN2 expression and response to chemotherapy}

All three criteria used to evaluate clinical responses to DCF chemotherapy showed significant differences between the RPN2negative and RPN2-positive groups (Table 2). The RECIST v1.0 criteria gave the RPN2-positive group PR 24, SD 25, PD 2 vs the RPN2-negative group CR 4, PR 17, SD $7(P=0.006)$. The WHO criteria gave the RPN2-postive group CR 1, PR 29, SD 20, PD 1 vs the RPN2-negative group CR 8, PR 16, SD $4(P<0.001)$. The histopathological criteria gave the RPN2-positive group grade 2: 2 , 
grade 1: 30, grade $0: 2, v s$ the RPN2-negative group grade 3: 5, grade 2: 4 , grade 1: $6(P<0.001)$.

\section{Response analysis by FDG-PET}

We also evaluated responses to DCF chemotherapy by SUV changes in primary oesophageal tumour. Median $\mathrm{SUV}_{\max }$ reduction rate was $55 \%$ in all ESCC patients; decreased SUV was observed in $92.4 \%$ (73 out of 79 ) after DCF treatment. Median $\mathrm{SUV}_{\max }$ reduction rate was $44 \%$ (range: -54.1 to $88.1 \%$ ) in the RPN2-positive group $(n=51$, Figure $2 \mathrm{~A}$ ) and $68 \%$ (range: -18.1 to $88.8 \%)$ in the RPN2-negative group $(n=28$, Figure $2 \mathrm{~B})$. The $S U V_{\text {max }}$ reduction rate significantly differed between the RPN2-negative and RPN2-positive groups $(P=0.004)$.

\section{RPN2 silencing increases sensitivity to docetaxel}

TE1 and TE14 cells expressed RPN2 mRNA at high levels as evaluated by real-time RT-PCR. We examined whether RPN2

Table 2 The correlation between RPN2 expression and response to chemotherapy

\begin{tabular}{|c|c|c|c|c|}
\hline \multirow[b]{2}{*}{$\begin{array}{l}\text { Therapeutic } \\
\text { value }\end{array}$} & \multirow[b]{2}{*}{$\begin{array}{l}\text { Total } \\
(n=79)\end{array}$} & \multicolumn{2}{|c|}{ RPN2 } & \multirow[b]{2}{*}{$P$-value } \\
\hline & & $\begin{array}{l}\text { Positive } \\
(n=51)\end{array}$ & $\begin{array}{c}\text { Negative } \\
(n=28)\end{array}$ & \\
\hline \multicolumn{4}{|l|}{ RECIST v 1.0} & 0.006 \\
\hline$C R$ & 4 & 0 & 4 & \\
\hline$P R$ & 41 & 24 & 17 & \\
\hline SD & 32 & 25 & 7 & \\
\hline PD & 2 & 2 & 0 & \\
\hline \multicolumn{4}{|l|}{ WHO criteria } & $<0.001$ \\
\hline$C R$ & 9 & 1 & 8 & \\
\hline PR & 45 & 29 & 16 & \\
\hline SD & 24 & 20 & 4 & \\
\hline PD & 1 & I & 0 & \\
\hline \multicolumn{4}{|l|}{ Histopathology } & $<0.001$ \\
\hline Grade 3 & 5 & 0 & 5 & \\
\hline Grade 2 & 6 & 2 & 4 & \\
\hline Grade I & 36 & 30 & 6 & \\
\hline Grade 0 & 2 & 2 & 0 & \\
\hline
\end{tabular}

Abbreviations: $C R=$ complete response; $P D=$ progressive disease; $P R=$ partial response; RECIST $=$ Response Evaluation Criteria in Solid Tumors; $\mathrm{SD}=$ stable disease; $\mathrm{WHO}=$ World Health Organization. Analyzed by Fisher's test. suppression altered sensitivity to docetaxel. Expression levels of RPN2 mRNA and protein were suppressed by RPN2-specific siRNA, as confirmed by RT-PCR and western blot analyses (Figure $3 \mathrm{~A}$ and $\mathrm{B}$ ). At $48 \mathrm{~h}$ after treatment with siRNA and docetaxel, there was substantial cell death induced by RPN2 siRNA compared with control siRNA (Figure 3C). We found that RPN2 suppression increased docetaxel sensitivity in both ESCC cells lines (Figure 3D).

\section{DISCUSSION}

In the present study, we have shown the clinical usefulness of RPN2 expression in endoscopic biopsy samples for predicting sensitivity to docetaxel-based chemotherapy. We also found that RPN2 suppression increases sensitivity to docetaxel in vitro. We evaluated responses to neoadjuvant chemotherapy using various methods, including clinical and pathological responses and decrease in SUV by FDG-PET. All the response evaluators demonstrated the efficacy of RPN2 as a response marker.

Reportedly, RPN2 is a key component in modulating docetaxel sensitivity in tumour cells by the glycosylating P-glycoproteins. Honma et al (2008) proposed that RPN2 may serve as a predictor for response to anticancer therapy rather than as a prognostic factor, and would be useful for selecting subjects who are likely to benefit for adjuvant chemotherapy in breast cancer. Furthermore, blocking RPN2 expression or function may induce a CR to chemotherapeutic drugs. The RPN2 gene may therefore represent a promising new target for RNAi therapeutics against multidrugresistant tumours (Honma et al, 2008). Most patients with ESCC, who present with advanced disease stages, are treated with chemotherapy followed by oesophagectomy, which has become a standard treatment option for patients with ESCC in Japan. We previously reported that a DCF regimen is tolerable as induction therapy (Watanabe et al, 2011). However, although substantial progress has been made in the treatment of this tumour, relapse or lack of response due to intrinsic or acquired resistance greatly reduces survival rates. Thus, identification of biomarkers that predict treatment response are needed to improve patient care.

This study has some limitations that warrant consideration. First, the sample size is relatively small. A larger independent series with more patients is needed to validate these results; for this reason, we are continuing to collect endoscopic biopsy specimens from ESCC patients. It is unclear whether RPN2 expression carries prognostic significance for ESCC patients who undergo oesophageal resection after docetaxel-based
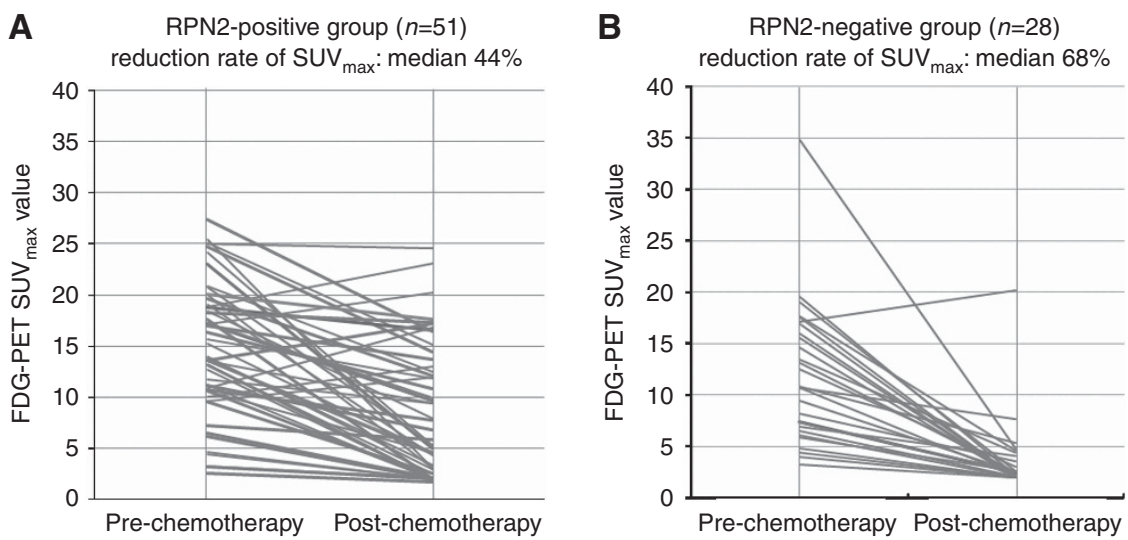

Figure 2 Changes in SUV during neoadjuvant chemotherapy in primary ESCC tumours. (A) Median SUV reduction rate was 44\% in the RPN2-positive group and (B) 68\% in the RPN2-negative group. The SUV $\max$ reduction rate between the RPN2-negative and RPN2-postive groups was significantly different $(P=0.004)$. 
A
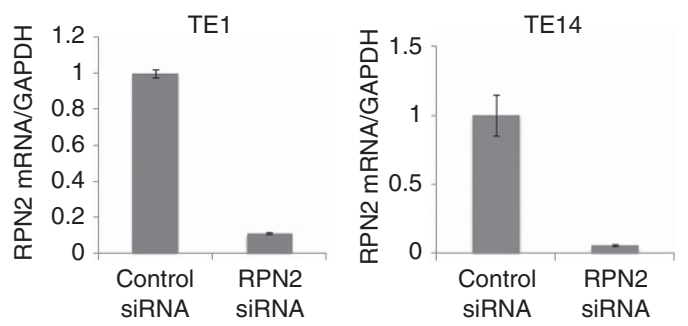

B

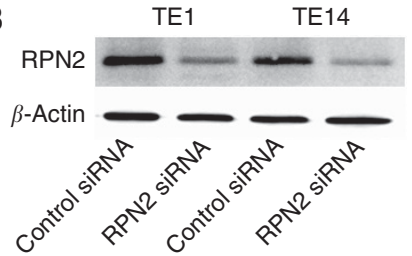

C
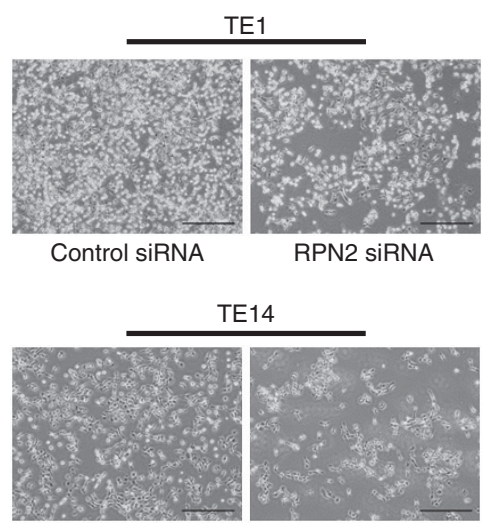

Control siRNA
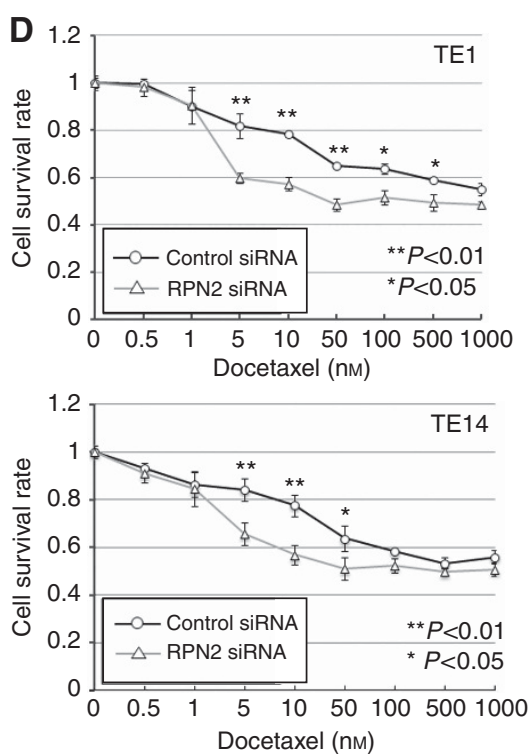

Figure 3 Suppression of RNP2 by siRNA enhances sensitivity to docetaxel. (A) RPN2 mRNA expression in TEI/I 4 cells was suppressed by RPN2 siRNA as confirmed using real-time quantitative PCR. (B) RPN2 protein was suppressed by siRNA as confirmed by western blot. (C) Phase-contrast micrograph of TEl/I 4 cells $48 \mathrm{~h}$ after treatment with RPN2 siRNAs or control siRNA in the presence of $10 \mathrm{~nm}$ docetaxel. Scale bar is $500 \mu \mathrm{m}$. (D) RPN2-suppressed cells were more sensitive to docetaxel than were control cells.

chemotherapy. There is no significant difference in overall survival and disease-free survival between RPN2-positive and RPN2negative groups currently, because of short follow-up period (data not shown). We are going to present relevant data later, when we have a larger number of samples and longer observed time. Second, as RPN2 induces glycosylation of P-glycoprotein and provokes membrane localisation, our data may indicate sensitivity to other anticancer drugs. However, we had no sufficient number of ESCC patients who received only 5-FU and CDDP regimen, and we could not completely rule out the possibility that RPN2 expression reflects CDDP and 5-FU sensitivity in ESCC cell lines; this too should be tested with a larger sample.

Biopsy under endoscopy is a routine medical examination for gastrointestinal malignancy. Immunohistochemical analysis of biopsy specimens is an easy and safe method of estimating tumour biological characteristics, thus enabling individualised treatment strategies. Ineffective chemotherapy is not only useless, but harmful in the neoadjuvant setting; prediction of chemotherapeutic response, which differ among patients and cancers, is therefore critical.

Previous studies described predictive molecules for therapeutic responses to docetaxel-based neoadjuvant chemotherapy in several cancers. For example, expression of $\beta$-tubulin - especially class III $\beta$-tubulin - correlated with poor overall survival and reduced response to taxanes, including docetaxel, in patients with advanced non-small-cell lung (Rosell et al, 2003), breast (Paradiso et al, 2005; Rouzier et al, 2005), ovarian (Mozzetti et al, 2005; Ohishi et al, 2007), gastric cancers (Urano et al, 2006), and head and neck squamous carcinoma (Koh et al, 2009). MicroRNA-200c regulates class III $\beta$-tubulin directly, and thus restores sensitivity to docetaxel in ovarian (Cochrane et al, 2010; Leskela et al, 2011) and breast cancer (Cochrane et al, 2009). CYP3A4 metabolises docetaxel in the liver, and is an important factor in determining docetaxel's efficacy and toxicity. Patients with low CYP3A4 expression showed significantly higher response rates than those with high CYP3A4 expression (Miyoshi et al, 2005). These molecules have important implications in docetaxel-induced cell death and can be predictive markers for docetaxel-based chemotherapy. However, no useful predictive markers for docetaxel in ESCC have yet been established. This is the first report that shows the possible use of RPN2 as a predictive marker for docetaxel-based chemotherapy in ESCC.

In conclusion, RPN2 expression in endoscopic biopsy specimens may predict response to docetaxel-based chemotherapy. Although a larger validation study is needed, the findings in this study have important clinical implications for patients receiving neoadjuvant chemotherapy for ESCC.

\section{ACKNOWLEDGEMENTS}

We thank Mrs Y Taniguchi, Mr Y Miyake and Ms N Yokoyama for their excellent technical assistance. This work was supported in part by the following grants and foundations: Japan Society for the Promotion of Science (JSPS) Grant-in-Aid for Scientific Research (grant number 23791550), Takeda Science Foundation 2010, Okukubo Memorial Fund for Medical Research in Kumamoto University School of Medicine 2010, Uehara Memorial Foundation 2010 and the Yokoyama Foundation for Clinical Pharmacology 2011.

Supplementary Information accompanies the paper on British Journal of Cancer website (http://www.nature.com/bjc)

\section{REFERENCES}

Akiyama H, Tsurumaru M, Udagawa H, Kajiyama Y (1994) Radical lymph node dissection for cancer of the thoracic esophagus. Ann Surg 220: 364-372, discussion 372-373
Ancona E, Ruol A, Santi S, Merigliano S, Sileni VC, Koussis H, Zaninotto G, Bonavina L, Peracchia A (2001) Only pathologic complete response to neoadjuvant chemotherapy improves significantly the long term survival 
of patients with resectable esophageal squamous cell carcinoma: final report of a randomized, controlled trial of preoperative chemotherapy versus surgery alone. Cancer 91(11): 2165-2174

Ando N, Iizuka T, Ide H, Ishida K, Shinoda M, Nishimaki T, Takiyama W, Watanabe H, Isono K, Aoyama N, Makuuchi H, Tanaka O, Yamana H, Ikeuchi S, Kabuto T, Nagai K, Shimada Y, Kinjo Y, Fukuda H (2003) Surgery plus chemotherapy compared with surgery alone for localized squamous cell carcinoma of the thoracic esophagus: a Japan Clinical Oncology Group Study-JCOG9204. J Clin Oncol 21(24): 4592-4596

Ando N, Kato H, Igaki H, Shinoda M, Ozawa S, Shimizu H, Nakamura T, Yabusaki H, Aoyama N, Kurita A, Ikeda K, Kanda T, Tsujinaka T, Nakamura K, Fukuda H (2012) A randomized trial comparing postoperative adjuvant chemotherapy with cisplatin and 5-fluorouracil versus preoperative chemotherapy for localized advanced squamous cell carcinoma of the thoracic esophagus (JCOG9907). Ann Surg Oncol 19: 68-74

Ando N, Ozawa S, Kitagawa Y, Shinozawa Y, Kitajima M (2000) Improvement in the results of surgical treatment of advanced squamous esophageal carcinoma during 15 consecutive years. Ann Surg 232(2): 225-232

Brucher BL, Weber W, Bauer M, Fink U, Avril N, Stein HJ, Werner M, Zimmerman F, Siewert JR, Schwaiger M (2001) Neoadjuvant therapy of esophageal squamous cell carcinoma: response evaluation by positron emission tomography. Ann Surg 233(3): 300-309

Cochrane DR, Howe EN, Spoelstra NS, Richer JK (2010) Loss of miR-200c: a marker of aggressiveness and chemoresistance in female reproductive cancers. J Oncol 2010: 821717

Cochrane DR, Spoelstra NS, Howe EN, Nordeen SK, Richer JK (2009) MicroRNA-200c mitigates invasiveness and restores sensitivity to microtubule-targeting chemotherapeutic agents. Mol Cancer Ther 8(5): 1055-1066

Honma K, Iwao-Koizumi K, Takeshita F, Yamamoto Y, Yoshida T, Nishio K, Nagahara S, Kato K, Ochiya T (2008) RPN2 gene confers docetaxel resistance in breast cancer. Nat Med 14(9): 939-948

Kelsen DP, Ginsberg R, Pajak TF, Sheahan DG, Gunderson L, Mortimer J, Estes N, Haller DG, Ajani J, Kocha W, Minsky BD, Roth JA (1998) Chemotherapy followed by surgery compared with surgery alone for localized esophageal cancer. N Engl J Med 339(27): 1979-1984

Koh Y, Kim TM, Jeon YK, Kwon TK, Hah JH, Lee SH, Kim DW, Wu HG, Rhee CS, Sung MW, Kim CW, Kim KH, Heo DS (2009) Class III betatubulin, but not ERCC1, is a strong predictive and prognostic marker in locally advanced head and neck squamous cell carcinoma. Ann Oncol 20(8): 1414-1419

Leskela S, Leandro-Garcia LJ, Mendiola M, Barriuso J, Inglada-Perez L, Munoz I, Martinez-Delgado B, Redondo A, de Santiago J, Robledo M, Hardisson D, Rodriguez-Antona C (2011) The miR-200 family controls beta-tubulin III expression and is associated with paclitaxel-based treatment response and progression-free survival in ovarian cancer patients. Endocr Relat Cancer 18(1): 85-95

Miyoshi Y, Taguchi T, Kim SJ, Tamaki Y, Noguchi S (2005) Prediction of response to docetaxel by immunohistochemical analysis of CYP3A4 expression in human breast cancers. Breast Cancer 12(1): 11-15

Mozzetti S, Ferlini C, Concolino P, Filippetti F, Raspaglio G, Prislei S, Gallo D, Martinelli E, Ranelletti FO, Ferrandina G, Scambia G (2005) Class III beta-tubulin overexpression is a prominent mechanism of paclitaxel resistance in ovarian cancer patients. Clin Cancer Res 11(1): 298-305

Ohishi Y, Oda Y, Basaki Y, Kobayashi H, Wake N, Kuwano M, Tsuneyoshi $\mathrm{M}$ (2007) Expression of beta-tubulin isotypes in human primary ovarian carcinoma. Gynecol Oncol 105(3): 586-592

Overman MJ, Kazmi SM, Jhamb J, Lin E, Yao JC, Abbruzzese JL, Ho L, Ajani J, Phan A (2010) Weekly docetaxel, cisplatin, and 5-fluorouracil as initial therapy for patients with advanced gastric and esophageal cancer. Cancer 116(6): 1446-1453

Paradiso A, Mangia A, Chiriatti A, Tommasi S, Zito A, Latorre A, Schittulli F, Lorusso V (2005) Biomarkers predictive for clinical efficacy of taxolbased chemotherapy in advanced breast cancer. Ann Oncol 16(Suppl 4): iv14-iv19

Rosell R, Scagliotti G, Danenberg KD, Lord RV, Bepler G, Novello S, Cooc J, Crino L, Sanchez JJ, Taron M, Boni C, De Marinis F, Tonato M, Marangolo M, Gozzelino F, Di Costanzo F, Rinaldi M, Salonga D, Stephens C (2003) Transcripts in pretreatment biopsies from a three-arm randomized trial in metastatic non-small-cell lung cancer. Oncogene 22(23): 3548-3553

Rouzier R, Rajan R, Wagner P, Hess KR, Gold DL, Stec J, Ayers M, Ross JS, Zhang P, Buchholz TA, Kuerer H, Green M, Arun B, Hortobagyi GN, Symmans WF, Pusztai L (2005) Microtubule-associated protein tau: a marker of paclitaxel sensitivity in breast cancer. Proc Natl Acad Sci USA 102(23): 8315-8320

Urano N, Fujiwara Y, Doki Y, Kim SJ, Miyoshi Y, Noguchi S, Miyata H, Takiguchi S, Yasuda T, Yano M, Monden M (2006) Clinical significance of class III beta-tubulin expression and its predictive value for resistance to docetaxel-based chemotherapy in gastric cancer. Int J Oncol 28(2): 375-381

Watanabe M, Nagai Y, Kinoshita K, Saito S, Kurashige J, Karashima R, Hirashima K, Sato N, Imamura Y, Hiyoshi Y, Baba Y, Iwagami S, Miyamoto Y, Iwatsuki M, Hayashi N, Baba H (2011) Induction chemotherapy with docetaxel/cisplatin/5-Fluorouracil for patients with node-positive esophageal cancer. Digestion 83(3): 146-152

Yamasaki M, Miyata H, Tanaka K, Shiraishi O, Motoori M, Peng YF, Yasuda T, Yano M, Shiozaki H, Mori M, Doki Y (2011) Multicenter phase I/II study of docetaxel, cisplatin and fluorouracil combination chemotherapy in patients with advanced or recurrent squamous cell carcinoma of the esophagus. Oncology 80(5-6): 307-313

This work is published under the standard license to publish agreement. After 12 months the work will become freely available and the license terms will switch to a Creative Commons Attribution-NonCommercial-Share Alike 3.0 Unported License. 